\title{
The ionospheric condition and GPS positioning performance during the 2013 tropical cyclone Usagi event in the Hong Kong region
}

Shiwei $\mathrm{Yu}^{1,2}$ and Zhizhao $\mathrm{Liu}^{1,2^{*}}$

\begin{abstract}
The ionosphere plays a critical role in the electromagnetic waves in communication systems such as the global positioning system (GPS). However, it is suspected that the strong convection during the tropical cyclone (TC) events can be a trigger to anomalous electron density variation in the ionosphere. This study analyzed the variation of three ionosphere-related parameters based on the GPS data including scintillation index S4, cycle slips, and total electron content (TEC) rate (TECR) during the tropical cyclone event (the 2013 TC Usagi) in the Hong Kong region. The results showed that the ionosphere-related parameters had a consistent significant increase on the second day after the Usagi made landfall near Hong Kong. Consequently, the positioning performance of GPS precise point positioning (PPP) and relative positioning modes was degraded. The degradation was 138\%, 181\%, and $\sim 460 \%$ in the east (root mean square (RMS) $0.050 \mathrm{~m}$ ), north (RMS $0.045 \mathrm{~m}$ ), and up (RMS $0.185 \mathrm{~m}$ ), respectively, compared with the RMS of $0.021 \mathrm{~m}$ in the east, $0.016 \mathrm{~m}$ in the north, and $0.033 \mathrm{~m}$ in the up on the normal day. Regarding the relative positioning, the positioning errors in the east (RMS $0.134 \mathrm{~m}$ ) and north (RMS $0.118 \mathrm{~m}$ ) directions were 7.1 and $\sim 7.9$ times, respectively, as large as the RMS of $0.019 \mathrm{~m}$ in the east and $0.015 \mathrm{~m}$ in the north on the normal day. The positioning errors in the up (RMS $0.513 \mathrm{~m}$ ) direction were 12.2 times larger than the RMS of $0.042 \mathrm{~m}$ on the normal day.
\end{abstract}

Keywords: Ionospheric scintillation, GPS precise point positioning (PPP), GPS relative positioning, Tropical cyclone (TC)

\section{Introduction}

The ionosphere is the layer of the Earth's atmosphere that is ionized by solar and cosmic radiation. Its height ranges from $\sim 50 \mathrm{~km}$ up to $\sim 1000 \mathrm{~km}$ above the Earth surface. The electron density in the ionosphere is the most important parameter characterizing the refractive index for radio waves (Gordon 1987). As the Global Positioning System (GPS) signals are carried on the radio waves, the different refractive indices which represent the

\footnotetext{
*Correspondence: Iszzliu@polyu.edu.hk

${ }^{1}$ Department of Land Surveying and Geo-Informatics, The Hong Kong

Polytechnic University, Hong Kong, China

Full list of author information is available at the end of the article
}

ionospheric condition lead to different ionospheric delays on the GPS observations. Therefore, it is crucial to study the quality of the GPS signals under different ionospheric conditions.

Besides the solar and cosmic radiation and geomagnetic activities, the convection in the lower atmosphere can also make an impact on the variation of electron density in the ionosphere. In the past 20 years, a considerable number of studies have been conducted to analyze the coupling effects between ionospheric disturbances and severe weather events, such as typhoon, tornadoes, and hurricanes (Lastovicka 2009; Mukhtarov et al. 2010). The GPS-derived total electron content (TEC) has been widely analyzed during severe 
weather events. Both the GPS-derived TEC and the F2 layer (foF2) increased within 2 days after the wind speed reached the peak during the Typhoons Ingrid (2005), George (2007), and Pancho (2008) in Australia (Li et al. 2018). The anomalous decrease of 3.8 TEC unit (TECU) and 2.1 TECU in the vertical TEC (VTEC) value from the monthly mean presented on the landfall day for the tropical cyclones Mahasen (2013) and Hudhud (2014), respectively, in the Indian sector (Guha et al. 2016). In addition, the obvious ionospheric disturbance in response to the 2015 Typhoon Dujuan in China was observed by analyzing the GPS-derived TEC sequences (Kong et al. 2017). Moreover, the close connection between the troposphere and low ionosphere was revealed through analyzing 41 tropical depression events in the North Atlantic Ocean in the period of 2004-2010 (Nina et al. 2017). The ionospheric responses to severe weather events can be explained as that the acoustic gravity waves (AGWs) are generated by the powerful convection during severe weather events. Then, the AGWs propagate up to the ionospheric altitude, leading to anomalous electron density variation (Xiao et al. 2007; Perevalova and Ishin 2011; Vanina-Dart and Sharkov 2016).

However, almost all the past work focused on using GPS-derived TEC to study the ionospheric responses to severe weather events. The other ionosphere-related parameters based on GPS data such as scintillation index $S_{4}$, cycle slips, TEC rate (TECR), as well as GPS positioning performance were rarely investigated. Although previous studies have been carried out to evaluate the GPS precise point positioning (PPP) performance during the period of ionospheric disturbance (Chen et al. 2008; Xu et al. 2012; Luo et al. 2018), these studies revealed that PPP performance was degraded by ionospheric scintillations that were induced by the powerful solar and geomagnetic activities. The PPP performance under complicated ionospheric condition induced by severe weather events was seldom analyzed. In addition, relative positioning under this condition has not been conducted yet either. In this study, the positioning performance during the severe weather event (the 2013 TC Usagi) in Hong Kong is analyzed and discussed.

In the following sections, the data set used in this study and the properties of the 2013 TC Usagi are introduced firstly. Three ionosphere-related parameters including the scintillation index $S_{4}$, cycle slips, and the TECR are analyzed during the period of the 2013 TC Usagi. Then, the GPS positioning performance in terms of PPP and relative positioning is analyzed. Finally, the conclusions drawn from the study are provided.

\section{Data}

\section{Tropical cyclone (Usagi 2013)}

The 2013 TC Usagi formed as a tropical depression over the western North Pacific about $1240 \mathrm{~km}$ east-northeast of Manila, Philippines, on 16 September 2013. The Usagi entered the South China Sea during the evening on 21 September. Then, it made landfall near Shanwei, Guangdong, China, about $160 \mathrm{~km}$ east-northeast of Hong Kong at about 12:00 UT (20:00 LT) on 22 September (Hong Kong Observatory 2015). The trajectory of the Usagi is depicted in Fig. 1. The dots with colors represent the locations of the tropical cyclone center at the corresponding time with interval of $6 \mathrm{~h}$. The locations of the Usagi at 00:00 UT (08:00 LT) of each day are labeled.

Figure 2 presents the brightness temperature image when the Usagi made landfall near Hong Kong. It is clear to see that Hong Kong was situated in the affected area of the Usagi with a distance of $\sim 160 \mathrm{~km}$ from the TC center. After landfall, the Usagi dissipated over the inland areas of Guangxi, China, in the afternoon on 23 September. According to the 2013 tropical cyclones report provided by Hong Kong Observatory (HKO) (Hong Kong Observatory 2015), the Usagi was the most intense tropical cyclone affecting Hong Kong in 2013.

\section{GPS data}

The GPS data used in this study were collected at the Hong Kong Satellite Positioning Reference Station Network (SatRef) stations (Chan and Li 2007), and the location of the stations is shown in Fig. 3. Three SatRef stations, i.e., HKPC (World Geodetic System 1984 (WGS84) ellipsoidal height: 18.130 m), HKOH (WGS84

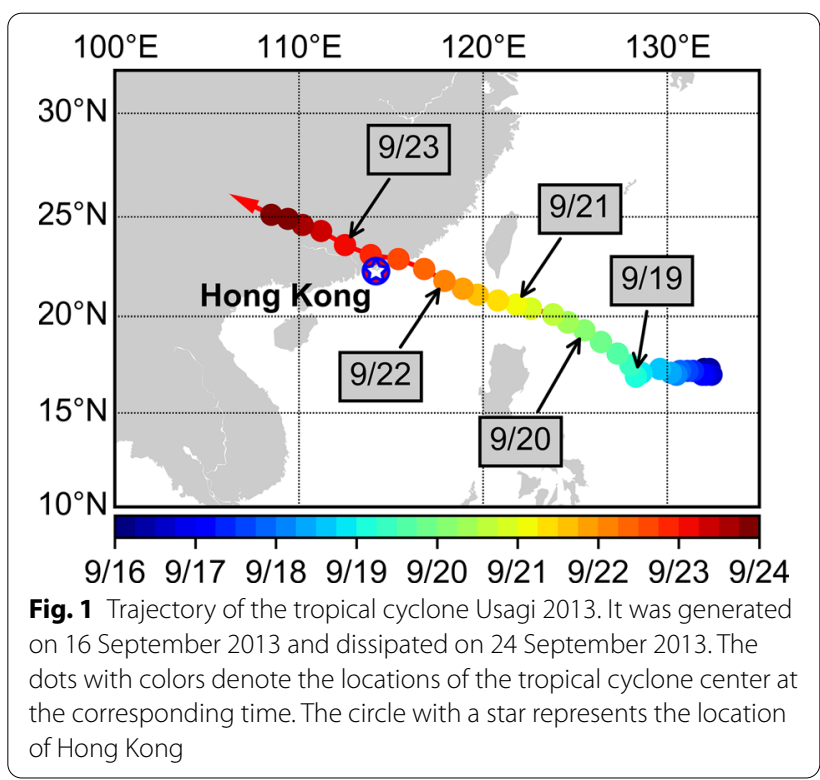




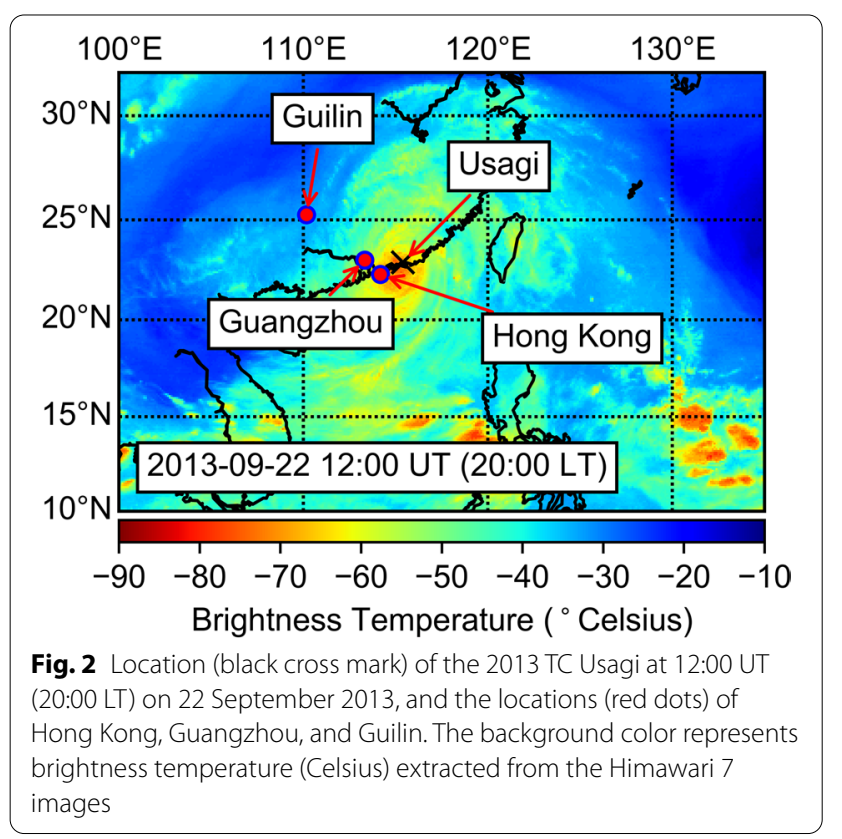

ellipsoidal height: $166.401 \mathrm{~m}$ ), and HKST (WGS84 ellipsoidal height: $258.705 \mathrm{~m}$ ), were selected and used in this study. They had an evenly spatial distribution in Hong Kong. The HKPC station is situated on the Peng Chau Island near the Lantau Island; the $\mathrm{HKOH}$ station is situated at Obelisk Hill on the Hong Kong Island; the HKST station is situated in Sha Tin. The GPS receivers and antennas of three stations have the same type, i.e., the Leica GR50 receiver and LEIAR25.R4 LEIT antenna. Besides the three SatRef GPS stations, one Ionospheric Scintillation Monitoring Receiver (ISMR) located in the south of Hong Kong was also used to study the ionospheric condition. This station can provide ionospheric scintillation in-phase and quadra-phase data at $100 \mathrm{~Hz}$ and carrier phase measurements at $50 \mathrm{~Hz}$ (Liu et al. 2013).

\section{lonospheric condition}

The ionospheric condition during the TC Usagi was analyzed in terms of scintillation index $\mathrm{S}_{4}$, occurrence rate of cycle slips, and TECR. Firstly, the variations of Kp, Dst,

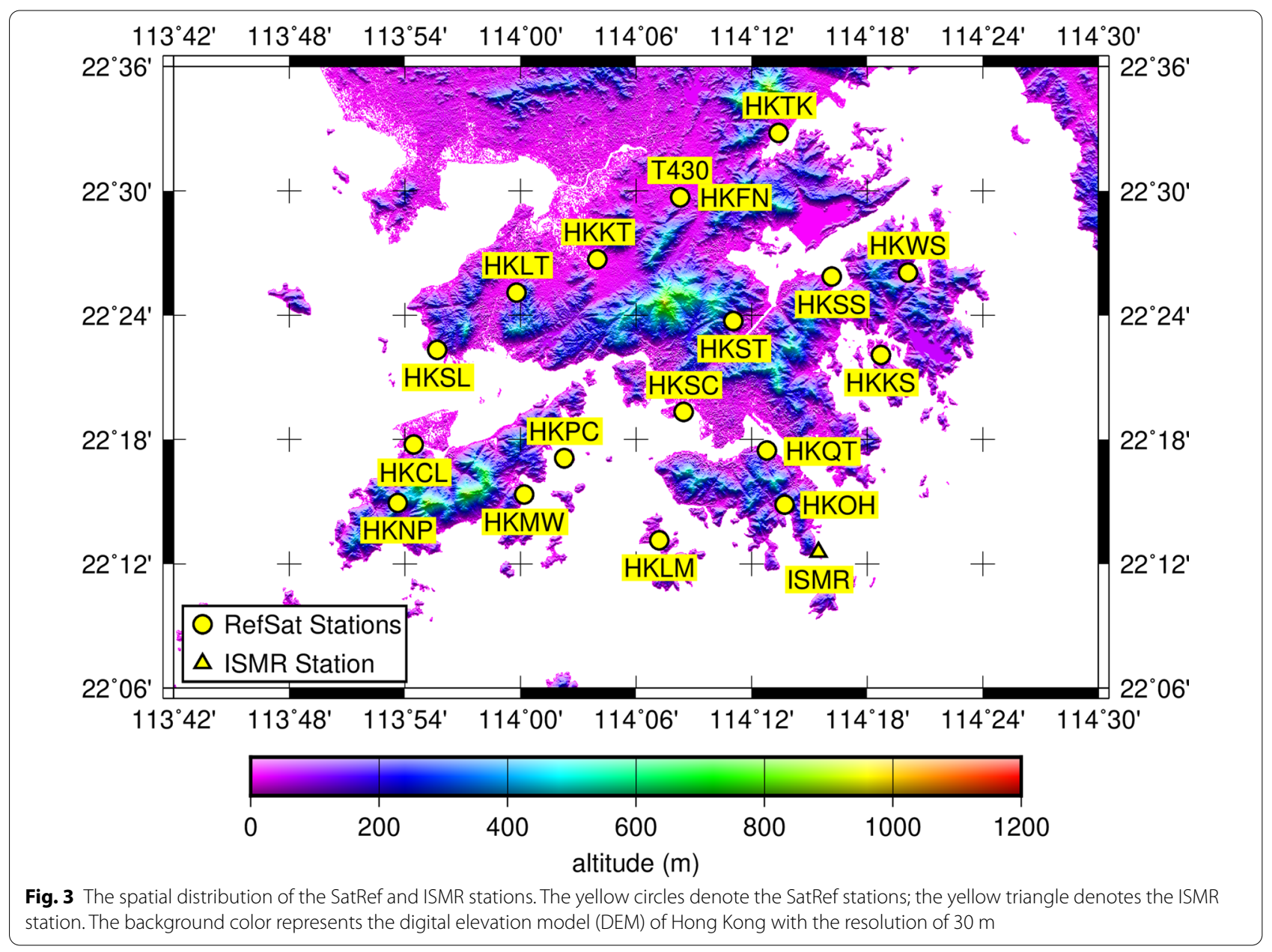


and F10.7 (Rostoker 1972) indices during the Usagi were studied because the strong geomagnetic and solar activities can also induce the ionospheric disturbance (Moeketsi et al. 2007; Brunini and Azpilicueta 2010; Guo et al. 2017). For a quiet geomagnetic condition, the Kp index should be smaller than 3 (Mungufeni et al. 2016), and the Dst index should be larger than - $20 \mathrm{nT}$ (Gulyaeva and Arikan 2017). For a relatively quiet solar condition, the F10.7 index should be smaller than 150 sfu (Tapping 2013). According to the variations of the indices as shown in Fig. 4, there were no strong geomagnetic or solar activities during the 2013 TC Usagi. The Kp index varies below 3 with the mean of 1.3 during the period from 13 September to 12 October. The variation of Dst index confirms that the geomagnetic condition was quiet during the Usagi with the average value of $-7.8 \mathrm{nT}$, which is much larger than $-20 \mathrm{nT}$. As for the solar condition, the F10.7 index is very stable with the mean of $108.3 \mathrm{sfu}$, which indicates a relatively quiet solar condition.

Furthermore, we also investigated two other solarrelated indices, i.e., X-ray flux and electron flux, to further confirm the solar condition. The data were retrieved from the National Oceanic and Atmospheric Administration (NOAA)/National Aeronautics and Space Administration (NASA) Geostationary Operational Environmental Satellite (GOES) 15 satellite. The results are shown in

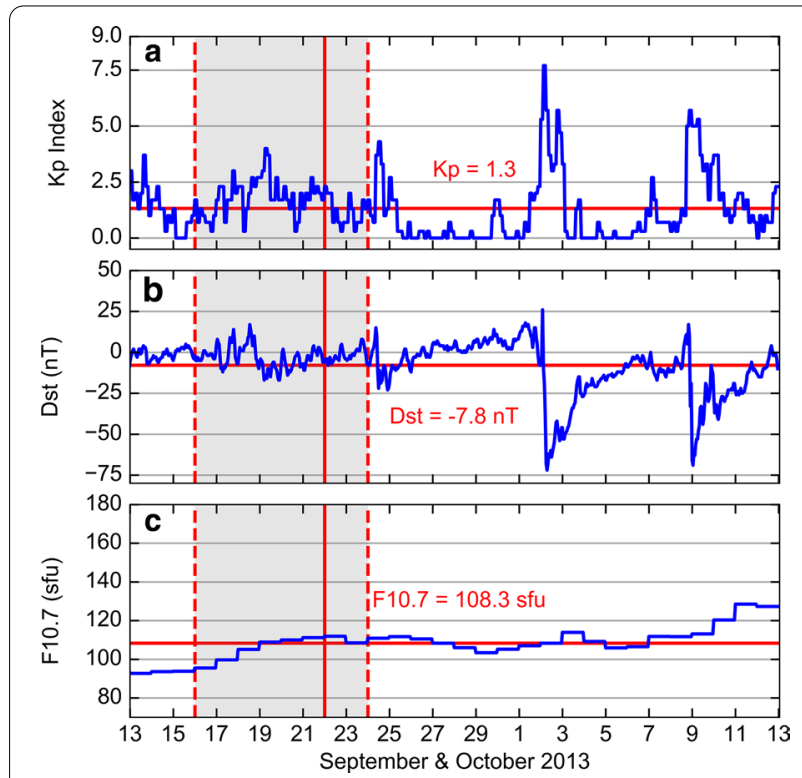

Fig. 4 The indices of $\mathrm{Kp}(\mathbf{a})$, Dst (b), and F10.7 (c) during the period from 13 September to 12 October 2013. The period from 16 to 24 September represented as a gray background area between two vertical dashed lines is the life cycle of the Usagi. The red solid horizontal lines denote the mean value of the indices. The red solid vertical line denotes the TC's landfall near Hong Kong on 22 September 2013
Fig. 5. The X-ray flux measured at the wavelength of $0.1-$ $0.8 \mathrm{~nm}$ varied stably without significant increases during the TC period including the TC landfall day. There were no intensive solar X-ray flares of X-class (X-radiation flux larger than $10^{-4} \mathrm{~W} / \mathrm{m}^{2}$ for wavelength between 0.1 and $0.8 \mathrm{~nm}$ ) or M-class (X-radiation flux between $10^{-5} \mathrm{~W} /$ $\mathrm{m}^{2}$ and $10^{-4} \mathrm{~W} / \mathrm{m}^{2}$ ) during the TC period (16 to $24 \mathrm{Sep}-$ tember), while the recorded solar X-ray flares of Class $\mathrm{C}$ (X-radiation flux between $10^{-6} \mathrm{~W} / \mathrm{m}^{2}$ and $10^{-5} \mathrm{~W} / \mathrm{m}^{2}$ ) were too weak (their flux were lower than $4 \times 10^{-6} \mathrm{~W} /$ $\mathrm{m}^{2}$ ) to cause significant disturbances in the ionosphere. Figure $5 c$ shows the variation of E2 electron fluxes from 13 September 2013 and 11 October 2013. During this TC period, as denoted by the period of two vertical red dashed lines, it started to increase on 19 September and kept a high value larger than $1000 \mathrm{~cm}^{-2} \mathrm{~s}^{-1} \mathrm{sr}^{-1}$ between 20 and 24 September, which would affect the operation of spacecraft systems (Forsyth et al. 2020). However, the reason for this high electron flux cannot be easily attributed to the solar radiations and geomagnetic activities, because other indices, including Kp, Dst, F10.7, X-ray

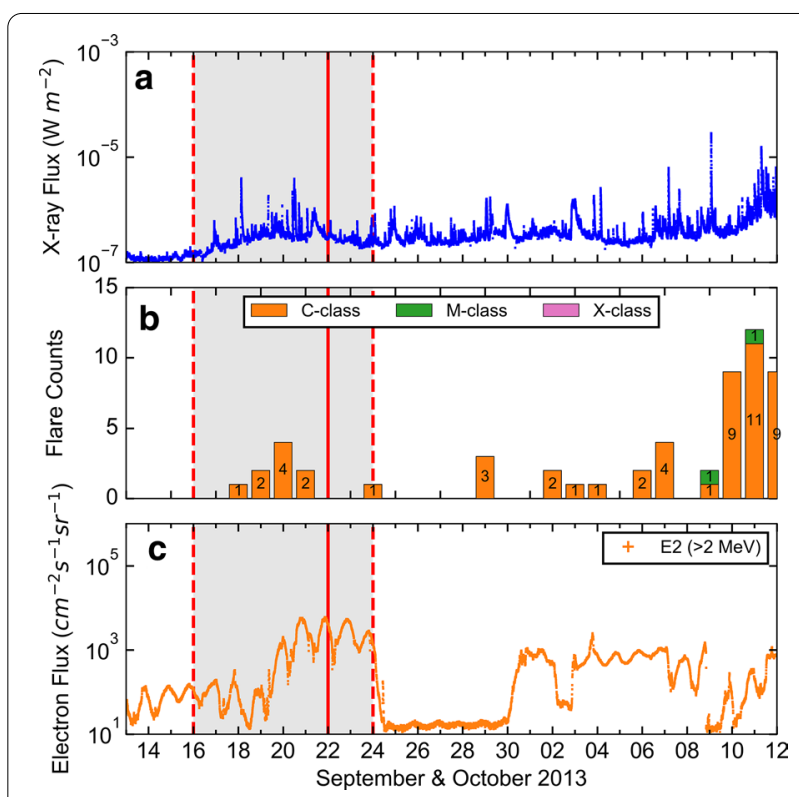

Fig. 5 Time series of $X$-ray (a), solar $X$-ray flare count (b), and electron flux (c) during the period from 13 September to 11 October 2013, which were measured by the GOES 15 geostationary satellite. Solar X-ray flux (https://satdat.ngdc.noaa.gov/sem/goes/data/ avg/2013/09/goes15/netcdf/) was measured at the wavelength of $0.1-0.8 \mathrm{~nm}$. Solar X-ray flare counts (https://hesperia.gsfc.nasa.gov/ goes/goes_event_listings/) are classified into 3 categories (C, M, and $\mathrm{X}$ classes of these flares). Electron flux (https://satdat.ngdc.noaa. gov/sem/goes/data/avg/2013/09/goes15/netcdf/) was measured at electron channels of E2 (>2 meV). The life cycle of the Usagi was from 16 to 24 September 2013, as represented by the gray background area between two vertical red dashed lines. The vertical red solid line denotes the TC's landfall near Hong Kong on 22 September 2013 
flux, and solar X-ray flare counts, clearly indicate a quiet geomagnetic and solar conditions during the TC period. Thus such an electron flux increase is very likely attributed to the TC event.

\section{Scintillation index $S_{4}$}

The electron density irregularities in the ionosphere can cause rapid amplitude and phase fluctuations, under some conditions, even the loss of lock of GPS signals. Such irregularities are called ionospheric amplitude and phase scintillations (Čokrlić and Galas 2013). Here, we just analyzed the amplitude scintillations during the period of the Usagi due to the strong correlation with the phase scintillations (Mushini et al. 2012). The amplitude scintillation can be described as the index of $S_{4}$. The formula of $\mathrm{S}_{4}$ can be written as (Van Dierendonck et al. 1993):

$$
S_{4}=\sqrt{\frac{\left\langle S I^{2}\right\rangle-\langle S I\rangle^{2}}{\langle S I\rangle^{2}}},
$$

where SI denotes the GPS signal intensity. $\langle\cdot\rangle$ represents the mean operation within the interval of interest, i.e., $60 \mathrm{~s}$ used in this study.

The ionospheric scintillation index $S_{4}$ was calculated based on the data from the ISMR station, and the GPS data observed above $30^{\circ}$ elevation angle were considered to reduce the multipath effects (Yang and Liu 2016b). As $S_{4}>0.3$ always indicates nonignorable scintillation activity (Muella et al. 2008), the number of scintillations with $S_{4}>0.3$ from 14 September to 12 October 2013 is shown in Fig. 6. It is noteworthy that there was no significant increase of scintillations during the period of the Usagi, even on the landfall day of 22 September 2013. However, a sudden increase of scintillations was observed on 24 September 2013, the second day after the Usagi made landfall. The number of scintillations reached up to 508 . Then, the count of scintillation events returned to normal levels on 26, 27, and 28 September 2013. Again, a slight increase of 185 and 100 scintillation events showed on September 29 and October 1, respectively. The number of scintillations returns to normal level afterwards except October 4.

\section{Cycle slips}

The electron density irregularities in the ionosphere can also interrupt the propagation of the GPS signals, known as cycle slips on the carrier phase measurements (Brunini and Azpilicueta 2010). Although other factors, i.e., (1) low signal-noise ratio (SNR) and multipath; (2) surrounding obstructions; (3) high dynamic state of the receiver; (4) failure in the receiver software can trigger the occurrence of cycle slips (Wang et al. 2016), the

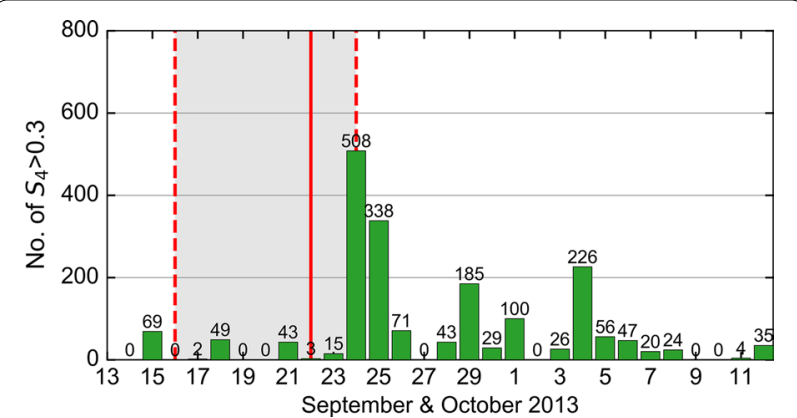

Fig. 6 Number of $S_{4}>0.3$ calculated from the ionospheric scintillation monitoring station during the period from 14 September to 12 October 2013. The life cycle of the Usagi was from 16 to 24 September 2013, as represented by the gray background area between two vertical red dashed lines. The vertical red solid line denotes the TC's landfall near Hong Kong on 22 September 2013

ionospheric disturbance is the major factor for the occurrence of cycle slips in this study because of the well-performed GPS receivers and carefully-selected locations of the Hong Kong SatRef network stations (Chan and Li 2007).

The sophisticated cycle slip detection algorithm based on the TECR and Melbourne-Wübbena wide lane (MWWL) observations was applied in this study (Liu 2011). The algorithm was validated under the active ionospheric condition (Cai et al. 2013). Figure 7 shows the total cycle slips for the HKOH, HKPC, and HKST stations on each day during the period from 14 September to 12 October 2013. The variation of the number of cycle slips on the GPS L1 and L2 signals shares the same pattern as the change of the scintillations. During the TC period, the occurrence rate of cycle slips on each day shows a stable variation. However, a sudden increase of cycle slips can be observed on 24 September 2013, the second day after the Usagi made landfall. The total number of cycle slips reaches up to $\sim 400$. Then, the number of cycle slips on September 27 falls back to a normal level. Again, the number of cycle slips bounces back on September 29 and October 1 with the value of $\sim 300$ and $\sim 200$. Afterwards, the number of cycle slips returns to a normal level.

\section{TECR}

The scintillations always indicate the electron density irregularities in the ionosphere. However, it is difficult to derive the electron density directly from the GPS measurements. Fortunately, the TECR along the satellite-receiver line-of-sight (LOS) can be derived to study the variation of the TEC in the ionosphere. Considering the large noise on the pseudorange measurements, 

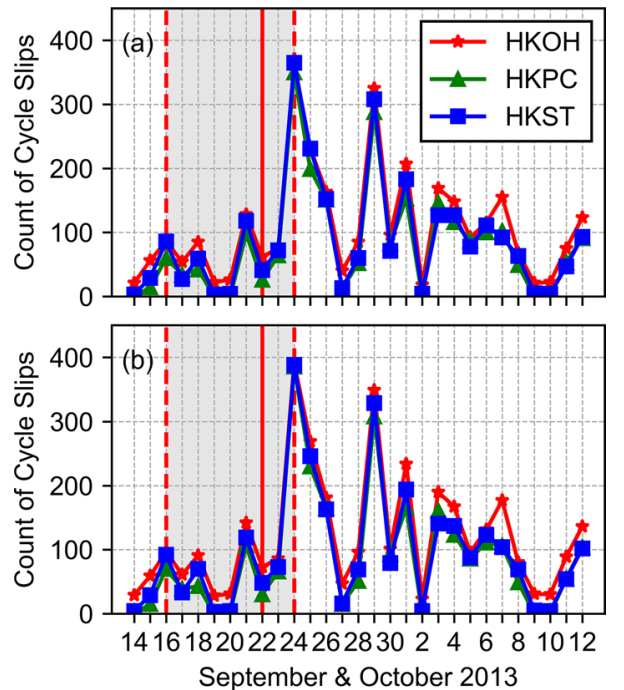

Fig. 7 Count of cycle slips calculated from the $\mathrm{HKOH}$ (red line with stars), HKPC (green line with triangles), and HKST (blue line with squares) stations from 14 September to 12 October 2013 on the GPS L1 (a) and L2 (b) signals. The life cycle of the Usagi was from 16 to 24 September 2013, as represented by the gray background area between two vertical red dashed lines. The vertical red solid line denotes the TC's landfall near Hong Kong on 22 September 2013

the carrier phase measurements are used to calculate the TECR in this study. The TECR can be calculated by differentiating the TEC values between two consecutive epochs. It can be written as (Liu 2011):

$$
\mathrm{TECR}=\frac{T E C(k)-T E C(k-1)}{\Delta t},
$$

where $\Delta t$ is the sample interval, in the unit of seconds.

$$
\operatorname{TEC}(k)=\frac{f_{1}^{2}\left\{\left[\lambda_{1} \varphi_{1}(k)-\lambda_{2} \varphi_{2}(k)\right]-\left[\lambda_{1} N_{1}-\lambda_{2} N_{2}\right]-b_{r}-b^{s}\right\}}{40.3 \times 10^{16}(\gamma-1)},
$$

where $\varphi_{1}(k)$ and $\varphi_{2}(k)$, in the unit of cycles, are the carrier phase measurements of the two frequencies $f_{1}$ and $f_{2}$, respectively, at the epoch $k ; \lambda_{1}$ and $\lambda_{2}$ are the wavelength of the frequencies $f_{1}$ and $f_{2}$, respectively, in unit of $\mathrm{m} /$ cycle; $N_{1}$ and $N_{2}$, in unit of cycles, are the ambiguities for the frequencies $f_{1}$ and $f_{2}$, respectively, which are often constants in a continuous arc; $b_{r}$ and $b^{s}$, in unit of meters, are the inter-frequency biases of the receiver $r$ and the satellite s, respectively, which can also be regarded as constants in a continuous arc; $\gamma=f_{1}^{2} / f_{2}^{2}$ is the ratio of the squared frequencies. Cycle slip detection and repair is needed before the TECR computation in order to make sure a continuous observation arc is obtained.

Figure 8 shows the variation of the TECR derived from the HKPC station in terms of mean and standard deviation (STD) for each GPS satellite during the period from 14 September to 12 October 2013. The variation of the mean value of the TECR is stable, changing within approximately $\pm 0.005 \mathrm{TECU} / \mathrm{sec}$ as shown in Fig. 8a. However, the change of the STD of the TECR shows a different way for each GPS satellite as shown in Fig. 8b. It is clear to see the TECR of GPS pseudorandom noise (PRN) 29 and GPS PRN 24 satellites has a relatively large standard deviation. It is suspected that the electron structure in the ionosphere along the LOS for GPS PRN 29 and GPS PRN 24 experienced an abnormal change. In addition, a sudden increase of the STD of the TECR for some GPS satellites can be observed on 24, 25, 29, and 30 September and 1 October 2013.

Figure 9 demonstrates the daily STD of the TECR for the $\mathrm{HKOH}, \mathrm{HKPC}$, and HKST stations during the period from 14 September to 12 October 2013. The STD of the TECR was averaged over the STD of the TECR of all the GPS satellites for each day. The change of the STD of the TECR for the HKOH, HKPC, and HKST stations is consistent with each other. It is worth noting that the change pattern of the STD of the TECR is the same as the change pattern of the scintillations and cycle slips. A stable period can be observed during the Usagi with an average value of $\sim 0.008 \mathrm{TECU} / \mathrm{sec}$. Then, the STD of the TECR suddenly increases to $\sim 0.016 \mathrm{TECU} / \mathrm{sec}$ on 24 September 2013. After 2 days' decrease, the STD of the TECR comes back to the normal value of $\sim 0.007 \mathrm{TECU} / \mathrm{s}$. Again, it bounces back on September 29 with the value of $\sim 0.013$ TECU/s. Afterwards, the STD of the TECR returns to a normal level.

\section{The connection between the TC and ionospheric disturbances}

The ionospheric disturbance occurred in the context of the clear geomagnetic and solar condition. It is suspected that the strong convection like TCs generates the AGWs, especially during the landfall period when the strong convection interacted with rough terrains, strengthening the AGWs power to propagate to the ionospheric layer (Chen et al. 2016; Chou et al. 2017; Kong et al. 2017).

Our findings show that the strong ionospheric disturbances occurred on the second day after the TC made landfall near Hong Kong. Moreover, the ionospheric disturbances often presented during the period from 12:00 UT (20:00 LT) to 18:00 UT (02:00 LT), which will be provided in the following section. It shows that the AGWs cannot trigger the ionospheric disturbances, i.e., scintillations, immediately. The reason is that the electron density in the ionosphere is relatively stable before sunset. After sunset, steep gradients of the electron above Hong Kong were generated from the eastward electric field (Song et al. 2017; Lou et al. 2019). The two factors, upward AGWs and steep gradients of the electron, jointly 


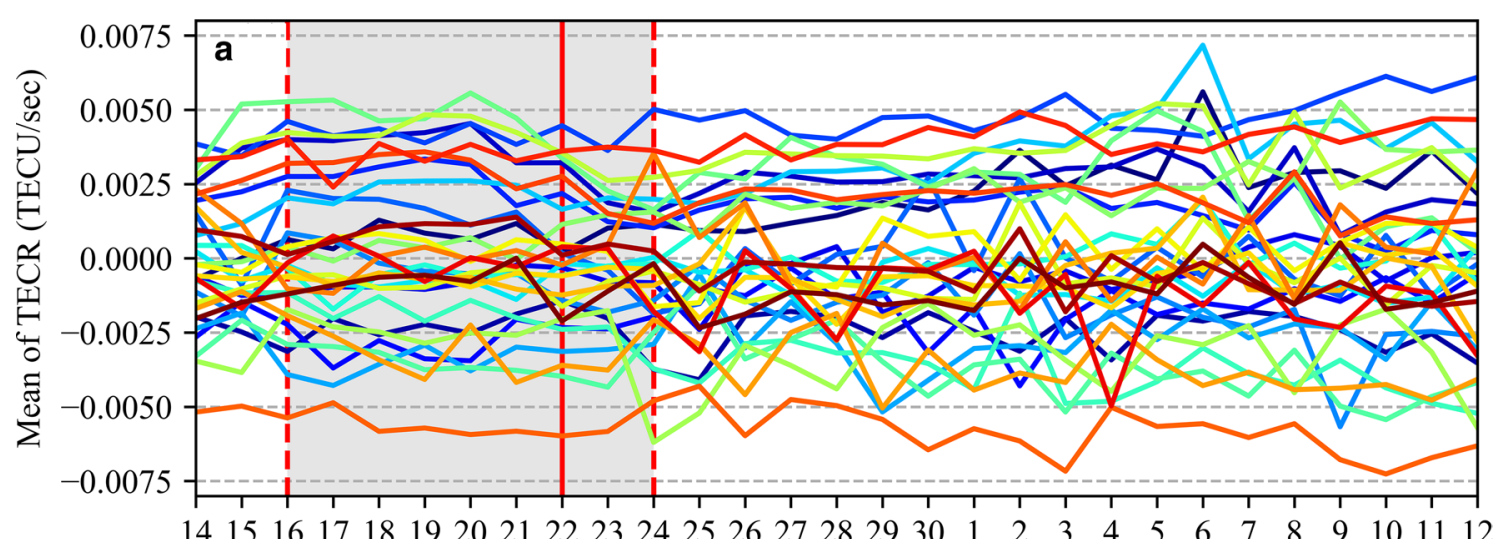

Date in September \& October 2013

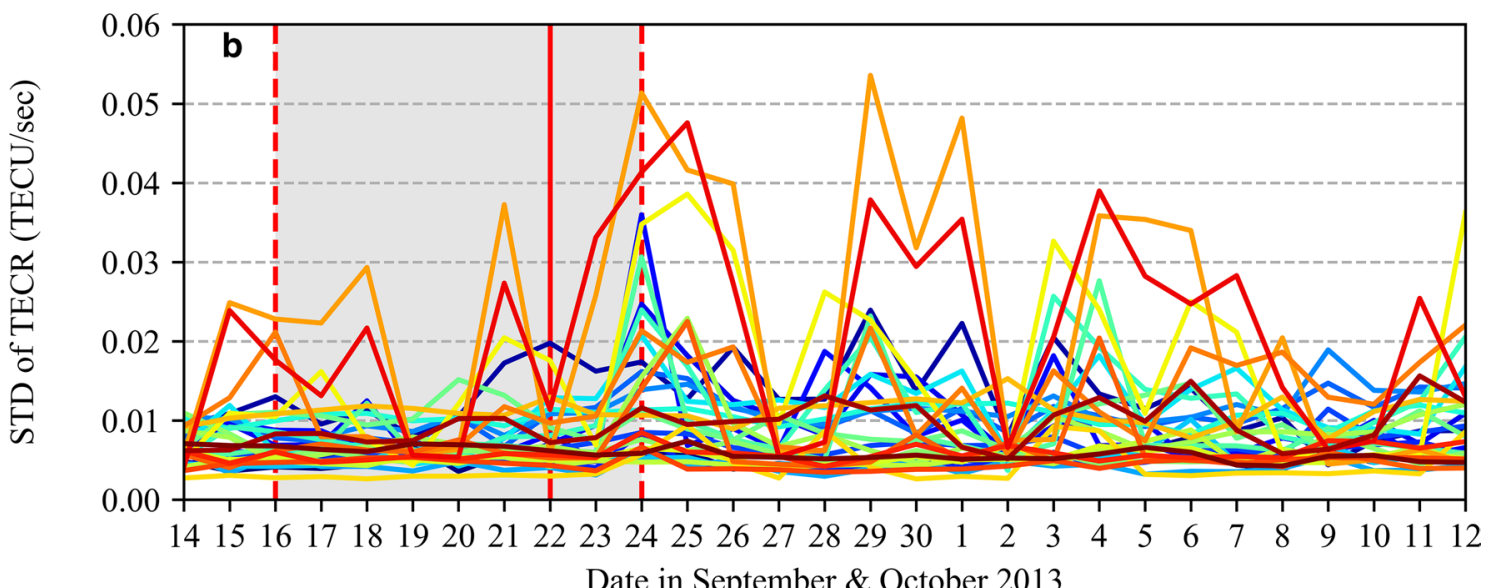

$\begin{array}{llllllllllllllllll}\text { G01 } & \text { G03 } & \text { G05 } & \text { G07 } & \text { G09 } & \text { G11 } & \text { G13 } & \text { G15 } & \text { G17 } & \text { G19 } & \text { G21 } & \text { G23 } & \text { G25 } & \text { G27 } & \text { G29 } & \text { G31 }\end{array}$

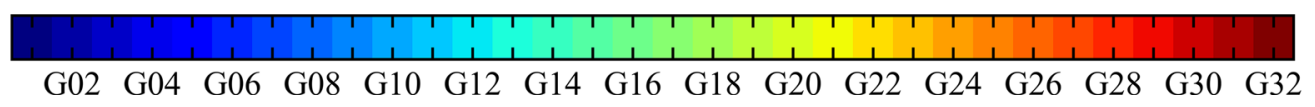

Fig. 8 Daily mean and STD of the TECR (unit:TECU/sec) derived from the HKPC station for each GPS satellite during the period from 14 September to 12 October 2013. Different colors denote different satellites. The life cycle of the Usagi was from 16 to 24 September 2013, as represented by the gray background area between two vertical red dashed lines. The vertical red solid line denotes the TC's landfall near Hong Kong on 22 September 2013

produced a more unpredictable electron distribution in the ionosphere. Consequently, strong ionospheric disturbances were triggered between 12:00 UT (20:00 LT) and 18:00 UT (02:00 LT) on 24 September 2013, the second day after the TC made landfall. Previous studies have shown that ionospheric disturbances occurred with one to four days delay after other TCs. Yang and Liu (2016a) found the ionospheric irregularities above Hong Kong on the second day after the 2012 TC Tembin made landfall over the southern coast of Taiwan. The ionospheric anomaly on the fourth day after the 2013 TC Haiyan made landfall over the eastern coast of Philippines was observed by Li et al. (2017). In Australia, the ionospheric disturbances occurred on the second day after the 2011
TC Yasi and the 2018 TC Marcus made landfall over the eastern and northern coast of Australia, respectively (Ke et al. 2019). Similar results were obtained for hurricanes near America, the ionospheric disturbances were observed 2 days delay after the 2005 Hurricane Katrina and Rita made landfall over the northern Gulf coast and the Texas/Louisiana border, and one day delay after the 2005 Hurricane Wilma made landfall near the northeastern Yucatan Peninsula (Polyakova and Perevalova 2011).

Furthermore, our findings show that there were strong ionospheric disturbances on 29 September and 1 October in terms of $\mathrm{S}_{4}$, number of cycle slips, and TECR. The disturbances were probably caused by the other TC, i.e., the TC 2013 Wutip. It passed by the south of Xisha Islands 


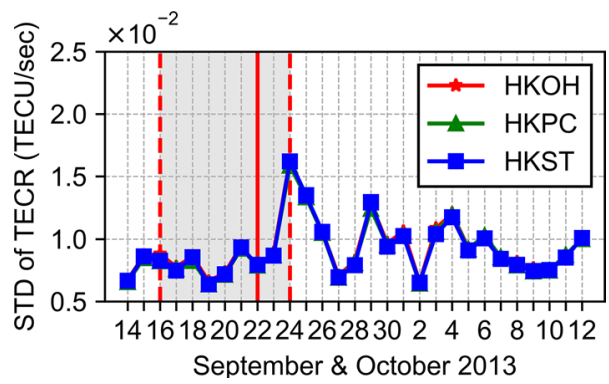

Fig. 9 Daily STD of the TECR (unit: TECU/s) for the HKOH (red line with stars), HKPC (green line with triangles), and HKST (blue line with squares) stations during the period from 14 September to 12 October 2013. The STD of TECR is calculated from the TECR of all the GPS satellites in a particular day. The life cycle of the Usagi was from 16 to 24 September 2013, as represented by the gray background area between two vertical red dashed lines. The vertical red solid line denotes the TC's landfall near Hong Kong on 22 September 2013

on 29 September with the intensity of Severe Typhoon and made landfall over the coast of central Vietnam on 30 September 2013 with the intensity of severe tropical storm. Compared with the TC Usagi, the TC Wutip had a weaker intensity. Therefore, the number of scintillations and cycle slips, and the value of TECR showed a lower level.

\section{GPS positioning performance}

As it has demonstrated that significant ionospheric scintillation occurred during Usagi, thus the positioning performance in PPP and relative positioning during the period of the tropical cyclone was analyzed. In addition, the postprocessing residuals of GPS observations were studied as well.

\section{GPS PPP}

The ionosphere-free pseudorange and carrier phase observations used in PPP can be expressed as the following (Leick et al. 2015):

$$
\begin{aligned}
& P_{r, I F}^{s}=\rho_{r}^{s}+c \cdot\left(d t_{r}-d t^{s}\right)+T_{r}^{s}+e_{I F}, \\
& \lambda_{I F} \varphi_{r, I F}^{s}=\rho_{r}^{s}+c \cdot\left(d t_{r}-d t^{s}\right)+T_{r}^{s}+\lambda_{I F} N_{I F}+\epsilon_{I F},
\end{aligned}
$$

where $P_{r, I F}^{S}$ in the unit of meter and $\varphi_{r, I F}^{S}$ in the unit of cycle are the pseudorange and carrier phase measurements from the satellite $\mathrm{s}$ to the receiver $\mathrm{r}$, respectively; $\rho_{r}^{s}$ represents the geometrical distance between the satellite and the receiver in the unit of meter; $c$ is the speed of light in vacuum in the unit of $\mathrm{m} / \mathrm{s} ; d t_{r}$ and $d t^{s}$ are the clock errors of the receiver and satellite in the unit of second, respectively; $T_{r}^{S}$ is the signal path delay due to the neutral atmosphere (primarily the troposphere) in the unit of meter; $\lambda_{I F}$ is the carrier phase wavelength of the ionosphere-free combination; $N_{I F}$ represents the noninteger ambiguity of ionosphere-free carrier phase combination; $e_{I F}$ and $\epsilon_{I F}$ are the relevant measurement noise components on pseudorange and carrier phase measurements, respectively.

The detailed models and strategies of PPP processing are listed in Table 1. Figure 10 shows examples of PPP results along with the ionospheric scintillation index at the HKPC station on four typical days. Figure 10a shows the PPP results on 19 September 2013 when no scintillations occurred. It is clear to see the PPP results in the components of east, north, and up are very stable with the RMS of $0.021 \mathrm{~m}, 0.016 \mathrm{~m}$, and $0.033 \mathrm{~m}$, respectively. It should be noted that the RMS was calculated

\begin{tabular}{|c|c|}
\hline Items & Models and strategies \\
\hline Observations & Pseudorange and carrier phase on GPS L1 and L2 \\
\hline Observation weighting & Elevation-dependent weight \\
\hline Sampling interval & $5 s$ \\
\hline Elevation mask angle & $5^{\circ}$ \\
\hline Satellite orbit & $\begin{array}{l}\text { Fixed using the products from the International } \\
\text { Global Navigation Satellite System Service (IGS) }\end{array}$ \\
\hline Satellite clock & Fixed using the products from the IGS \\
\hline Phase wind-up effect & Applied \\
\hline Site displacement & Applied \\
\hline Phase center offset and variation & IGS14.atx \\
\hline lonospheric delay & $\begin{array}{l}\text { First-order effect eliminated by ionospheric-free } \\
\text { linear combination }\end{array}$ \\
\hline Tropospheric delay & Estimated with the coordinates \\
\hline Ambiguity resolve & Estimated as real numbers \\
\hline Receiver coordinates & Estimated in kinematic mode \\
\hline
\end{tabular}

Table 1 Summary of PPP processing models and strategies 


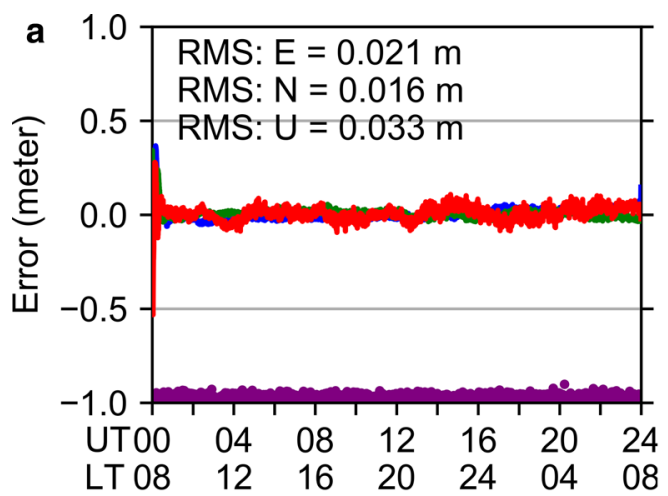

19 September 2013
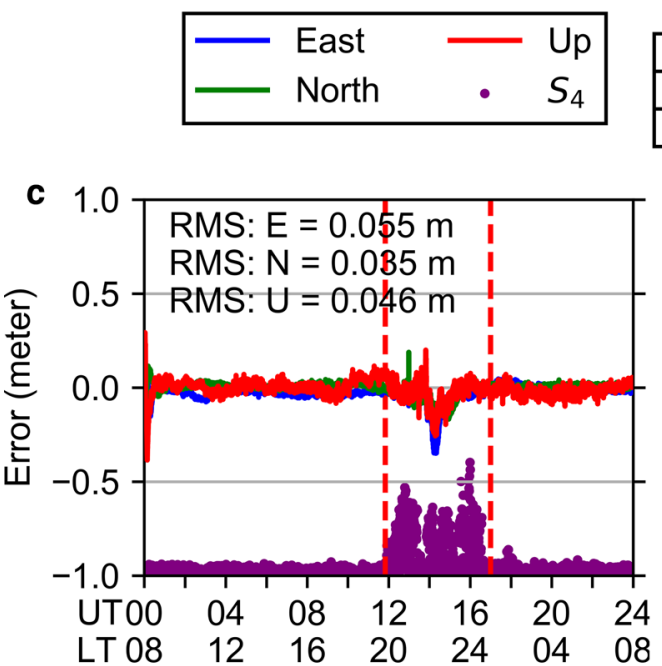

25 September 2013

\begin{tabular}{|l|c|c|c|}
\cline { 2 - 4 } \multicolumn{1}{c|}{} & $\mathrm{I}$ & $\mathrm{II}$ & $\mathrm{III}$ \\
\hline East & 0.030 & 0.098 & 0.016 \\
\hline North & 0.014 & 0.064 & 0.011 \\
\hline Up & 0.036 & 0.069 & 0.031 \\
\hline
\end{tabular}

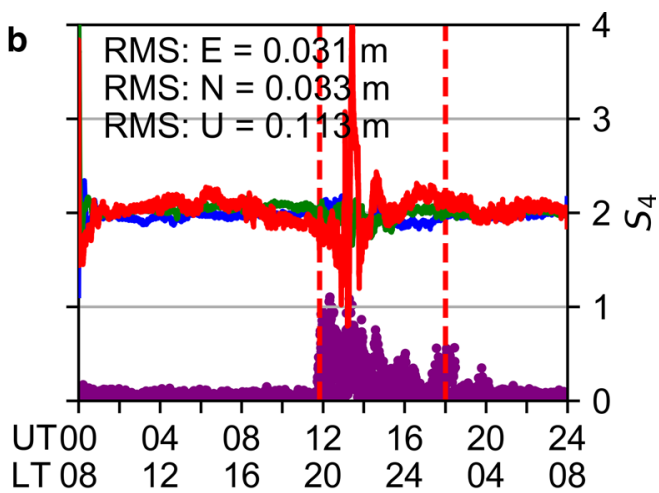

24 September 2013

\begin{tabular}{|l|c|c|c|}
\cline { 2 - 4 } \multicolumn{1}{c|}{} & I & II & III \\
\hline East & 0.014 & 0.050 & 0.015 \\
\hline North & 0.034 & 0.045 & 0.012 \\
\hline Up & 0.057 & 0.185 & 0.036 \\
\hline
\end{tabular}

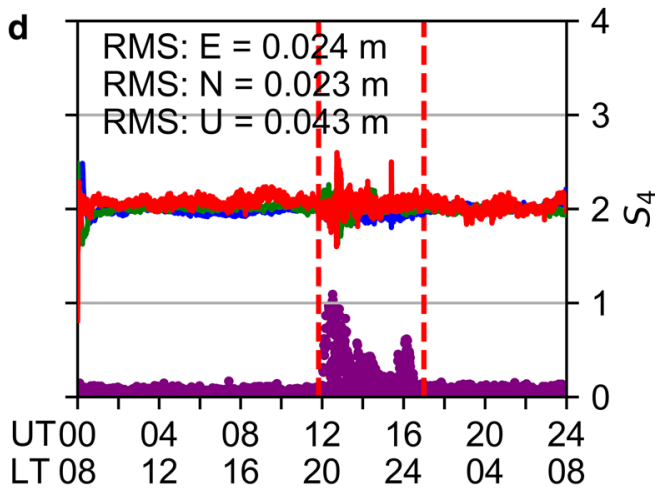

29 September 2013

\begin{tabular}{|l|c|c|c|}
\cline { 2 - 4 } \multicolumn{1}{c|}{} & \multicolumn{1}{c|}{} & II & III \\
\hline East & 0.017 & 0.037 & 0.015 \\
\hline North & 0.015 & 0.039 & 0.011 \\
\hline Up & 0.050 & 0.048 & 0.030 \\
\hline
\end{tabular}

Fig. 10 Positioning errors in the components of east, north, and up along with ionospheric scintillation index at the HKPC station on four typical days: 19 September 2013 (a) with no scintillations; 24 (b), 25 (c), and 29 (d) September 2013 with much more scintillations. The RMS of the positioning errors during different periods, as separated by the vertical dashed lines, is presented in the tables

after the convergence of positioning results. However, the PPP results on 24, 25, 29 September show degraded performances on the scintillation-impacted days, especially when the ionospheric scintillation index shows a significant increase. During the period of scintillations from 12:00 to 18:00 UT on 24 September 2013, the positioning results in the up direction have a large error with the RMS of $0.185 \mathrm{~m}, \sim 3.2$ times as large as that before the scintillation period, $\sim 5.1$ times as large as that after the scintillation period, and $\sim 5.6$ times as large as that on September 19. Concerning the positioning results in horizontal component, the RMS during the scintillation period is $0.050 \mathrm{~m}$ (east) and
$0.045 \mathrm{~m}$ (north), which increases by $138 \%$ and $181 \%$ compared with the results on the normal day (19 September 2013). The strong scintillation events on $25 \mathrm{Sep}-$ tember 2013 started at 12:00 UT and ended at 17:00 UT. The RMS of positioning errors in the east and north directions during the scintillation period on the day are $\sim 3.3$ and $\sim 6.1$ times as large as that before and after the scintillation period, respectively. They are $\sim 4.7$ and $\sim 4.0$ times larger than the results on the normal day September 19. The large positioning error in the up direction with the RMS of $0.069 \mathrm{~m}$ can be observed during the scintillation period. It is $\sim 1.9$ and $\sim 2.2$ times as large as the RMS before and after the scintillation 
periods, respectively, and $\sim 2.1$ times as large as that on the normal day September 19. As the scintillations weakened on 29 September 2013, the positioning performance on this day is better than those on 24 and 25 September 2013.

The unexpected loss of lock of tracked satellites, which reduces the available observations and considerably weakens the geometry, contributes to the degraded PPP performance in the scintillation period. In addition, the frequent loss of lock of tracked satellites makes it difficult for the PPP processing to handle cycle slips and ambiguity resolution. Furthermore, abnormal blunders on the pseudorange measurements are responsible for the PPP results with low accuracy (Zhang et al. 2014). Figure 11 depicts the spatial distribution of cycle slips on GPS L1 and L2 signals derived from the HKPC station along the trajectory of GPS satellites on 24 September 2013. It is clear to see that cycle slips occurred with even spatial distribution, which led to a weak geometry. In addition, the time series of cycle slips for each GPS satellite is shown in Fig. 12. Most cycle slips occurred in the scintillation period from 12:00 to 18:00 UT. That is why large positioning error occurred during the scintillation period.

Figure 13 provides two examples of the STD of residuals of GPS PRN 5 and 29 satellites for ionospherefree pseudorange and carrier phase measurements at
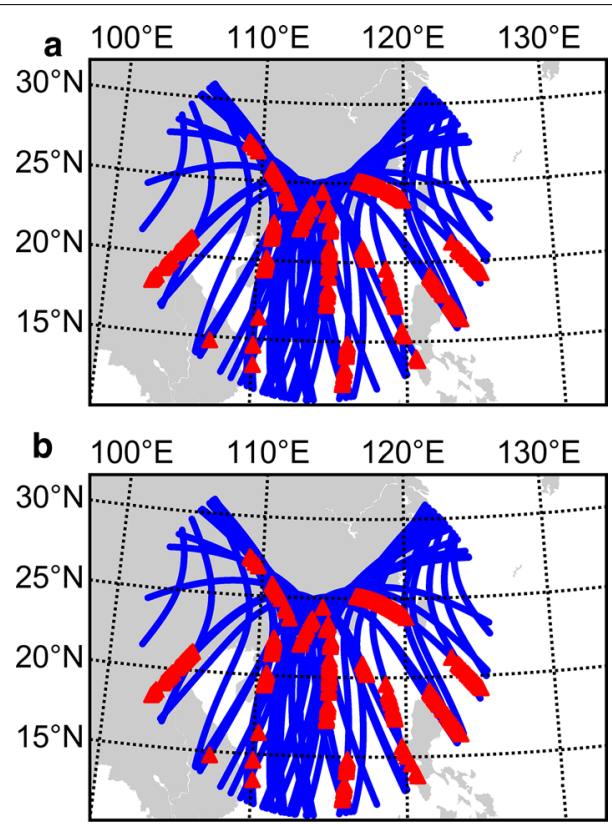

24 September 2013

Fig. 11 Spatial distribution of cycle slips on GPS L1 (a) and L2 (b) signals derived from the HKPC station on 24 September 2013. The blue lines denote the trajectory of the GPS satellites projected on the plane at the altitude of $350 \mathrm{~km}$. The red triangles on the blue line represent cycle slips the site of HKPC on 24 September 2013. The elevation and cycle slip information are also displayed. The postprocessing residuals on the ionosphere-free combination observations were calculated by canceling multiple errors, i.e., tropospheric delay, satellites' orbit and clock errors, phase wind-up effects, site displacement, and antenna phase center offset and variation. It is clear to see that the STD of residuals on pseudorange and carrier phase measurements had a significant increase when cycle slips occurred. It means that the ionospheric disturbance severely affects the quality of pseudorange and carrier phase measurements.

Figure 14 shows the STD of residuals on ionospherefree pseudorange and carrier phase measurements for the satellites which experienced cycle slips in three periods (1) 00:00-12:00 UT; (2) 12:00-18:00 UT; (3) 18:00-24:00 UT. Only observations with elevation

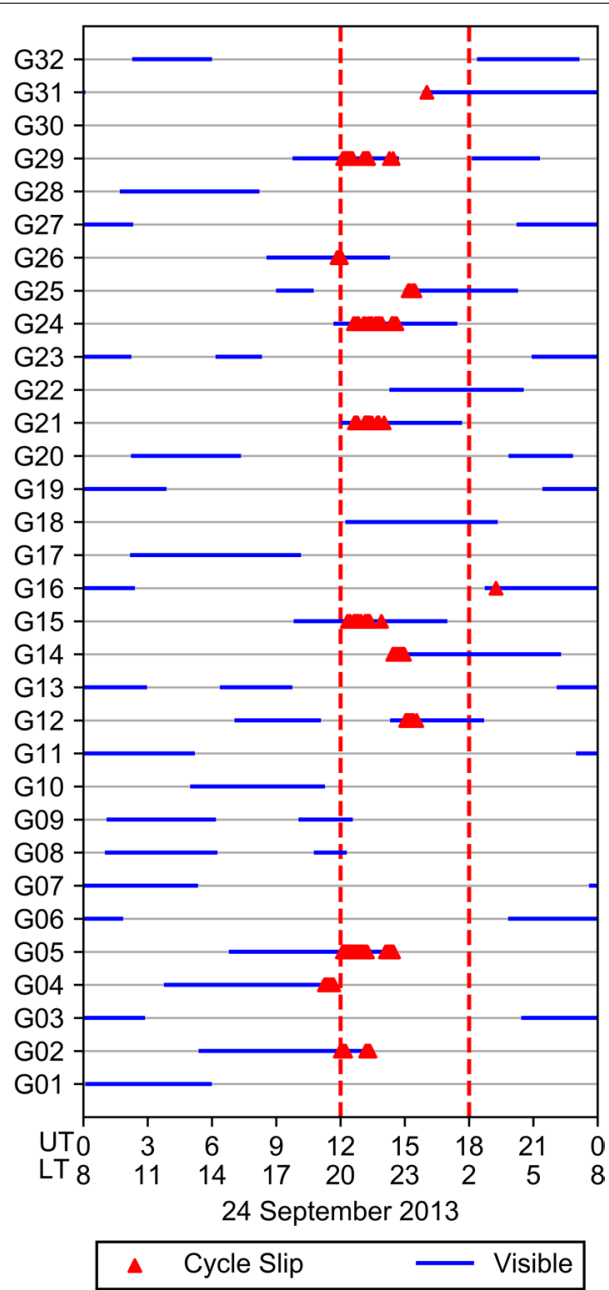

Fig. 12 Visibility and cycle slip of each GPS satellite derived from the HKPC station on 24 September 2013. The horizontal blue lines denote the visibility of the GPS satellites. The red triangles on the blue line are cycle slips. The scintillation period is from 12:00 to 18:00 UT represented with two vertical red dashed lines 
angle above $15^{\circ}$ were used for the sake of reducing multipath effects. It is obvious to note that when cycle slips occurred frequently during 12:00-18:00 UT, residuals had a larger standard deviation than those in the other two periods. For GPS PRN 26, the STD of residuals on pseudorange measurements shows a slight decrease during the period from 12:00 to 18:00 UT. That is because cycle slips exactly occurred at around 12:00 UT as shown in Fig. 12. For the GPS PRN 29, the residuals on the carrier phase measurements during the period from 18:00 to 24:00 UT had a larger standard deviation than that during the scintillation period. That is due to the low elevation angle as shown in Fig. 13. In addition, the low elevation angle is responsible for the slight large standard deviation on the carrier phase measurements during the period from 00:00 to 12:00 UT for the GPS PRN 12.

\section{GPS relative positioning}

The double-differenced observation equations on ionosphere-free pseudorange and carrier phase measurements can be expressed as (Leick et al. 2015):

$$
\begin{aligned}
& p_{m r}^{i j}=\rho_{m r}^{i j}+T_{m r}^{i j}+e_{m r}^{i j}, \\
& \lambda_{\mathrm{IF}} \varphi_{m r}^{i j}=\rho_{m r}^{i j}+\mathrm{T}_{m r}^{i r}+\lambda_{\mathrm{IF}} N_{m r}^{i j}+\epsilon_{m r}^{i j},
\end{aligned}
$$

where the superscript $i$ denotes the reference satellite, and $j$ denotes another satellite. The $m$ and $r$ are the master and rover receivers, respectively.

For the baseline solution, the elevation mask angle was set to $5^{\circ}$, and the integer ambiguities were estimated as real numbers. Figure 15 shows result examples of the baseline HKPC-HKOH on four typical days. The baseline solution on 20 September 2013 is shown
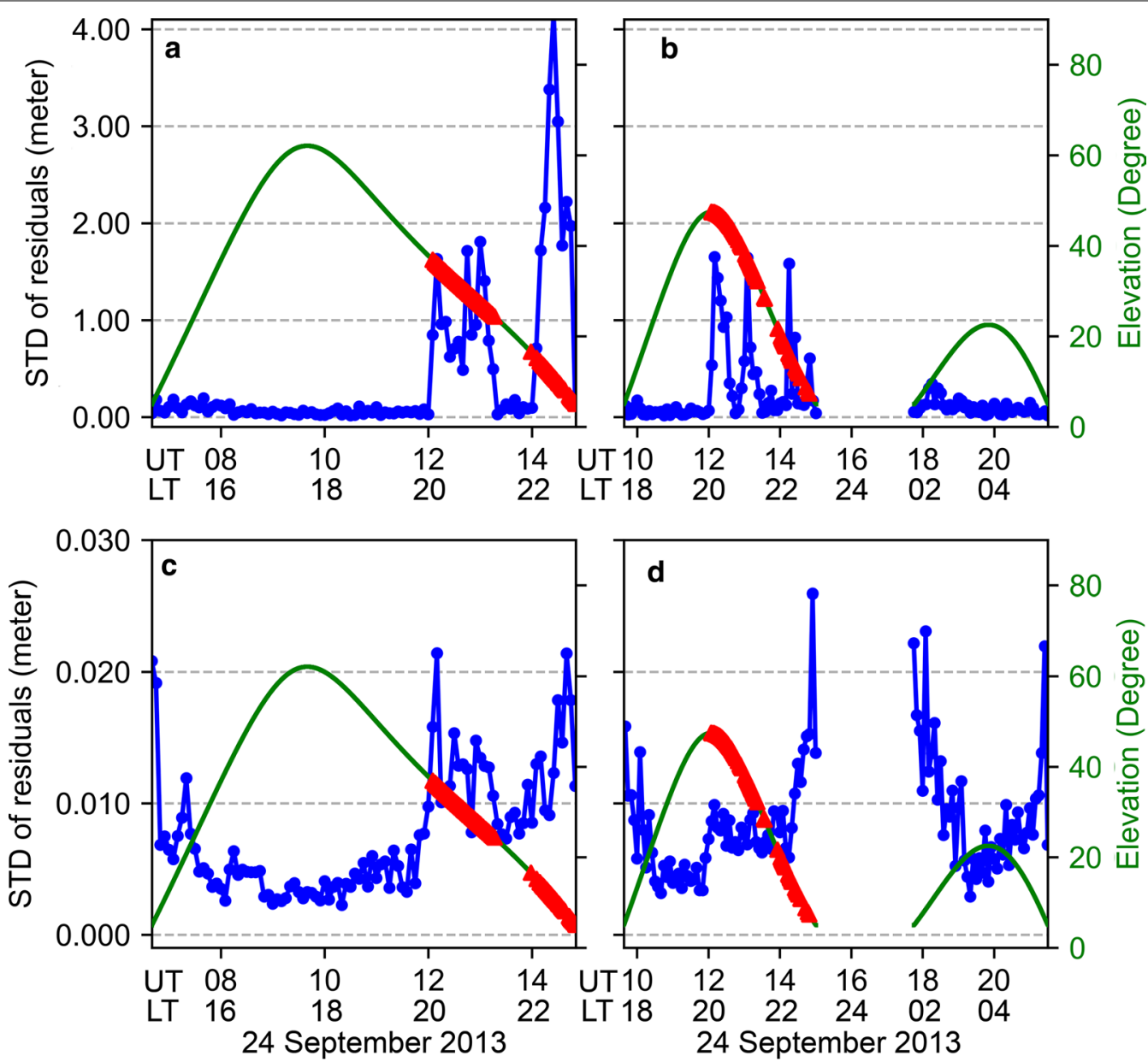

\section{$\longrightarrow$ residuals $\longrightarrow$ elevation $\quad$ cycle slips}

Fig. 13 STD of residuals of ionosphere-free measurements on pseudorange and carrier phase for GPS PRN 5 (a, c) and GPS PRN 29 (b, d) at the site of HKPC on 24 September 2013, along with the elevation and cycle slip information. The blue line with circles denotes STD of the residual for every $5 \mathrm{~min}$; the green lines denote the elevation angle; the red triangles represent cycle slips 


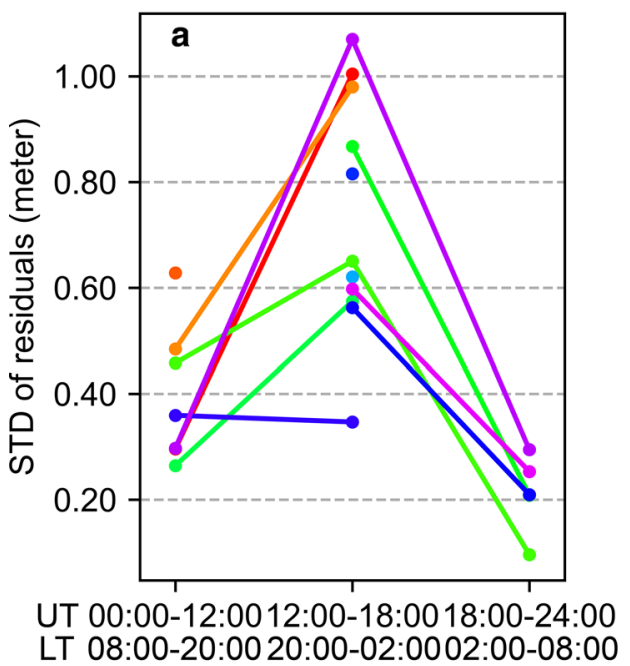

24 September 2013

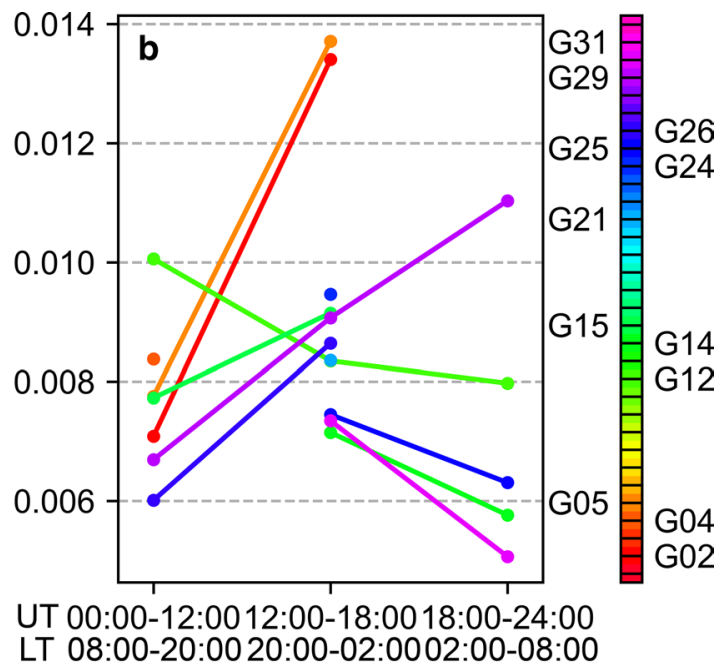

24 September 2013

Fig. 14 STD of residuals on ionosphere-free pseudorange (a) and carrier phase (b) measurements for the satellites which suffer cycle slips from aspects of three period (1) 00:00-12:00 UT; (2) 12:00-18:00 UT; (3) 18:00-24:00 UT at the site of HKPC on 24 September 2013. The isolated points without linkage with other points mean that the satellites are just visible in one of the three periods

in Fig. 15a. This day had no scintillations either. It is clear to see the solutions in east, north, and up directions have very good accuracy with RMS of $0.019 \mathrm{~m}$, $0.015 \mathrm{~m}$, and $0.042 \mathrm{~m}$, respectively. However, the solutions on 24, 25 and 29 September 2013 are severely affected by the scintillations. On 24 September 2013, the strongest scintillations occurred between 12:00 and 18:00 UT, and the RMS of baseline solution during this period is $0.134 \mathrm{~m}, 0.118 \mathrm{~m}$, and $0.513 \mathrm{~m}$ in the components of east, north, and up, respectively. The RMS in the east and north directions is $\sim 5.3$ times as large as the RMS before the scintillation period, $\sim 8.4$ times as large as the RMS after the scintillation period, and $~ 7.4$ times as large as the RMS on the normal day (20 September 2013). In the up direction, the RMS of $0.513 \mathrm{~m}$ during the scintillation period is $\sim 7.5$ times as large as the RMS before the scintillation period, $\sim 12.5$ times as large as the RMS after the scintillation period, and 12.2 times as large as the RMS on the normal day. As for the other 2 days (25 and 29 September 2013), similarly, scintillations show a significant impact on the baseline results and a larger bias is observed in the solution during the scintillation period.

Figure 16 provides three examples of the STD of residuals of GPS PRN 2, 12, and 18 satellites on ionospherefree pseudorange and carrier phase measurements for the baseline HKPC-HKOH on 24 September 2013. The elevation and cycle slip information are also displayed. The relatively large STD of residuals on the ionospherefree pseudorange measurements can be observed when the satellites experienced cycle slips. Compared with the STD of residuals on ionosphere-free pseudorange measurements, the STD of residuals on ionosphere-free carrier phase measurements shows a smaller increase when cycle slips occurred.

The STD of residuals on ionosphere-free pseudorange and carrier phase measurements for all the GPS satellites was analyzed in terms of three periods: (1) 00:00-12:00 UT; (2) 12:00-18:00 UT; (3) 18:00-24:00 UT as shown in Fig. 17. It is clear to see that a significant increase of the STD on the ionosphere-free pseudorange measurements between 12:00 and 18:00 UT can be observed, which means the pseudorange measurements are severely affected during the period of ionospheric disturbance. Compared with ionosphere-free pseudorange measurements, the STD of residuals of the ionosphere-free carrier phase measurements for baseline $\mathrm{HKPC}-\mathrm{HKOH}$ solution does not show a close relationship with the scintillations, which indicates that the carrier phase measurements were not degraded during the scintillation period.

\section{Conclusions}

The ionosphere observation in Hong Kong showed abnormal variation during the TC 2013 Usagi. The three GPS-based ionosphere-related parameters, i.e., scintillation index $\mathrm{S}_{4}$, cycle slip, and TECR, simultaneously showed a significant increase on the second day after the Usagi made landfall. The explanation for this phenomenon was that the AWGs was strengthened 

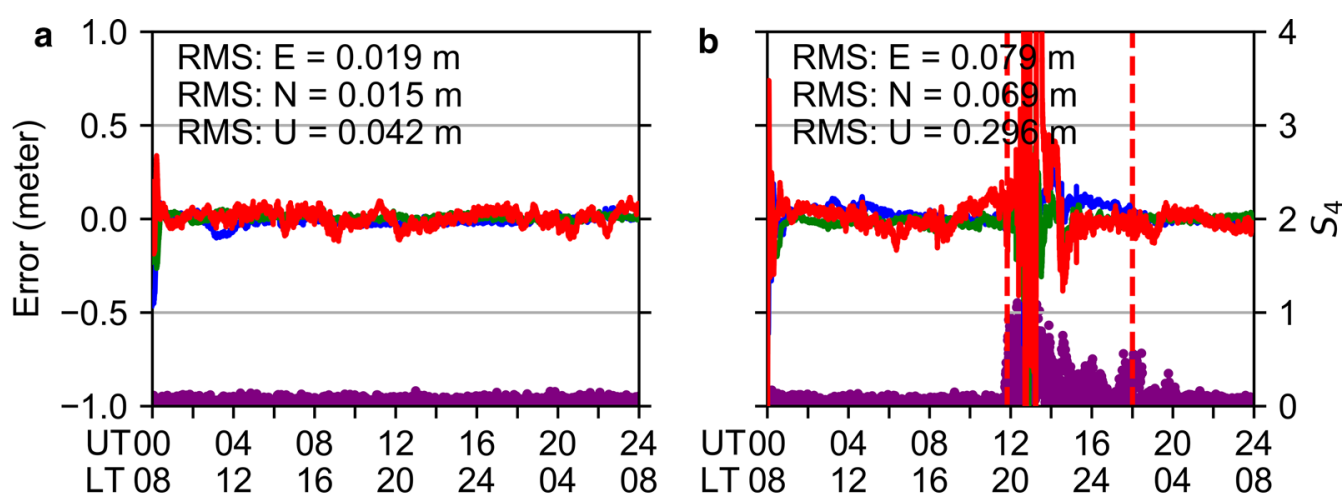

20 September 2013

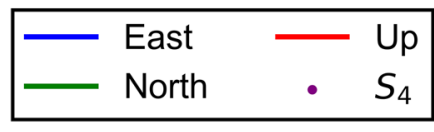

24 September 2013

\begin{tabular}{|l|c|c|c|}
\cline { 2 - 4 } \multicolumn{1}{c|}{} & $\mathrm{I}$ & II & III \\
\hline East & 0.024 & 0.134 & 0.019 \\
\hline North & 0.023 & 0.118 & 0.012 \\
\hline Up & 0.068 & 0.513 & 0.041 \\
\hline
\end{tabular}
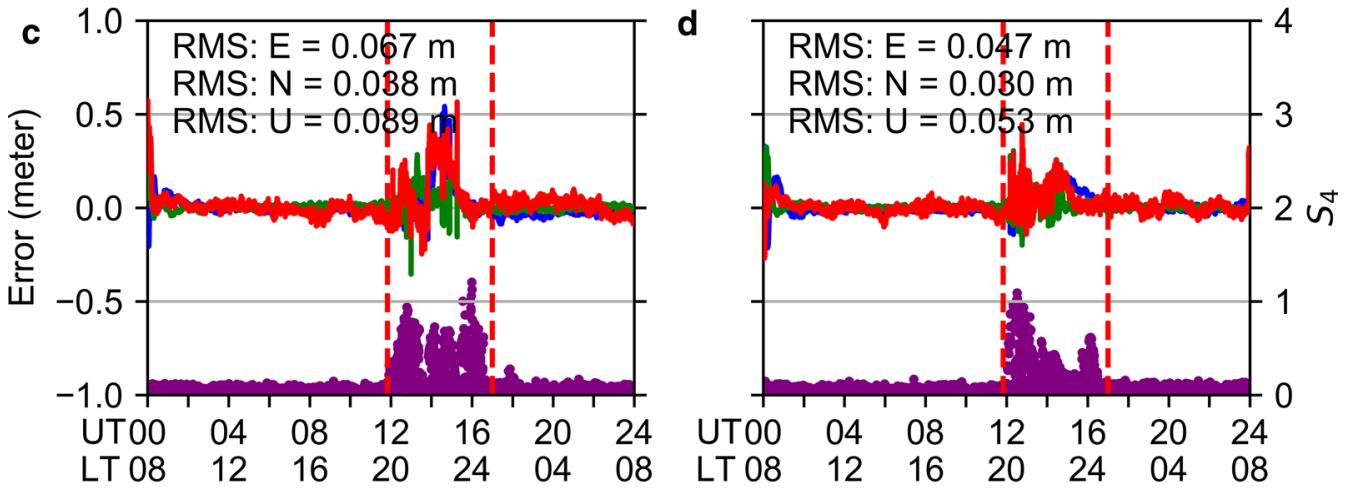

25 September 2013

\begin{tabular}{|l|c|c|c|}
\cline { 2 - 4 } \multicolumn{1}{c|}{} & \multicolumn{1}{c|}{} & II & III \\
\hline East & 0.010 & 0.122 & 0.035 \\
\hline North & 0.012 & 0.069 & 0.012 \\
\hline Up & 0.031 & 0.160 & 0.040 \\
\hline
\end{tabular}

29 September 2013

\begin{tabular}{|l|c|c|c|}
\cline { 2 - 4 } \multicolumn{1}{c|}{} & I & II & III \\
\hline East & 0.014 & 0.088 & 0.013 \\
\hline North & 0.008 & 0.055 & 0.012 \\
\hline Up & 0.028 & 0.083 & 0.042 \\
\hline
\end{tabular}

Fig. 15 Baseline solution of HKPC-HKOH in the components of east, north, and up along with ionospheric scintillation index on four typical days: 20 September 2013 without scintillations as shown in a, 24 September, 25 September, and 29 September with strong scintillations as shown in b-d. The RMS of the positioning errors during different periods separated by the vertical dashed lines is presented in the tables

during the TC landfall period. When the upward AWGs was combined with the eastward electric field after sunset, i.e., 20:00 LT to 02:00 LT, the ionospheric condition became more unstable and unpredictable. As a result, the ionospheric disturbances were observed between 20:00 LT and 02:00 LT on the second day after the TCs made landfall near Hong Kong.

The GPS positioning performance in PPP and relative positioning was also degraded by the ionospheric disturbances. The RMS of the GPS PPP errors on the ionosphere quiet day (19 September 2013) were $0.021 \mathrm{~m}, 0.016 \mathrm{~m}$, and $0.033 \mathrm{~m}$ in the components of east, north, and up, respectively. However, the RMS of the positioning errors on the second day after the Usagi made landfall (24 September 2013) were $0.050 \mathrm{~m}$, $0.045 \mathrm{~m}$, and $0.185 \mathrm{~m}$ in the components of east, north, and up, respectively. As for the relative positioning, the RMS of the positioning errors in the east and north directions during the period of TC-induced ionospheric disturbance (24 September 2013) were $0.134 \mathrm{~m}$ and $0.118 \mathrm{~m}$, which were $\sim 7.1$ and $\sim 7.8$ times as large as the RMS on the ionosphere quiet day, i.e., $0.019 \mathrm{~m}$ in the east direction and $0.015 \mathrm{~m}$ in the north direction. Furthermore, the positioning errors in the up (RMS $0.513 \mathrm{~m}$ ) direction during the period of TC-induced ionospheric disturbance could reach up to $\sim 12.2$ times 

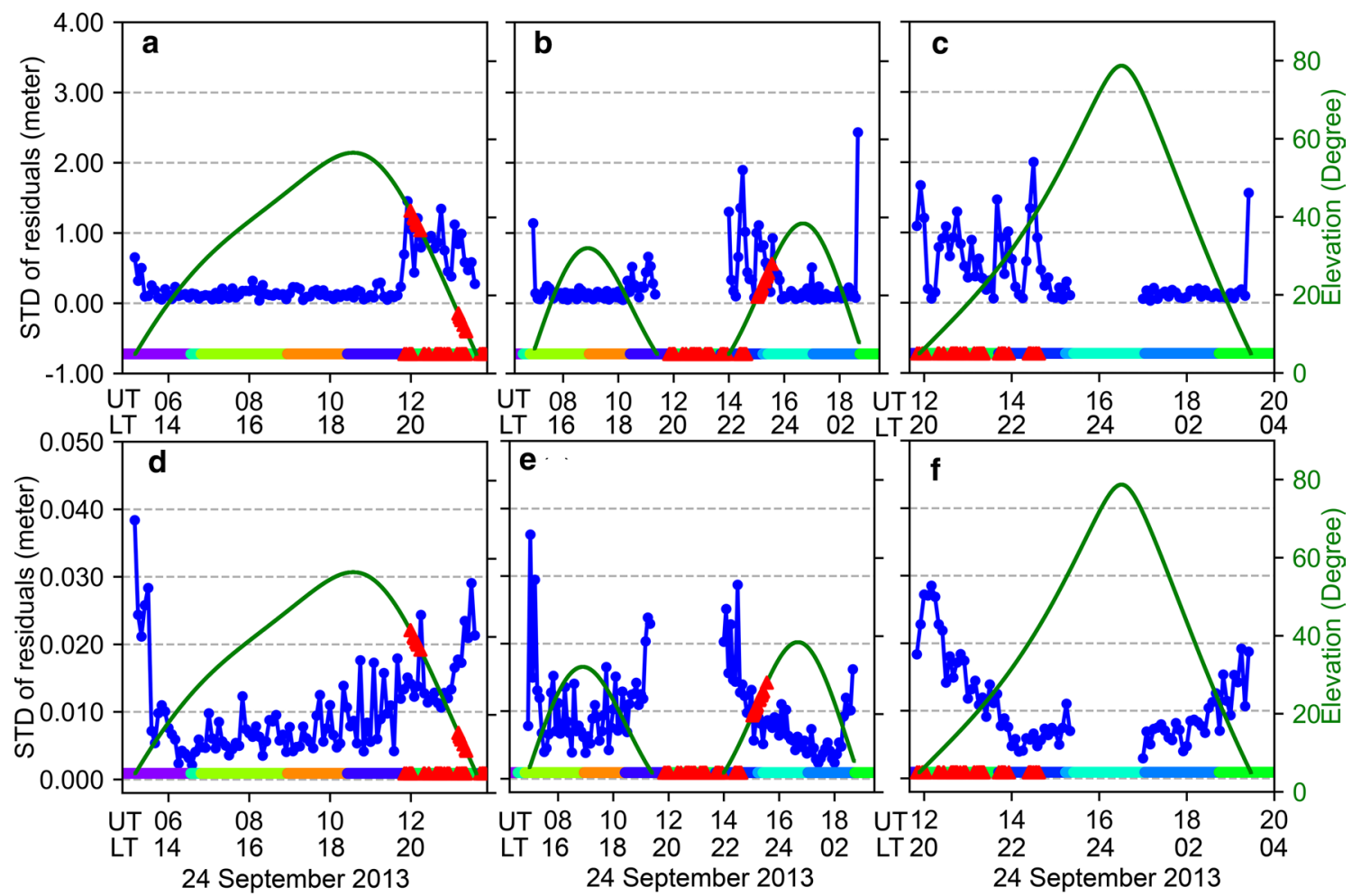

$\rightarrow$ residuals $\longrightarrow$ elevation $\quad$ cycle slips

Fig. 16 STD of residuals of ionosphere-free measurements on pseudorange and carrier phase GPS PRN 2 (a, d), GPS PRN 12 (b, e), and GPS PRN 18 $(\mathbf{c}, \mathbf{f})$ for the baseline HKPC-HKOH along with the elevation and cycle slip information on 24 September 2013. The blue line with circles denotes the STD of residuals for every 5 min; the green line denotes the elevation angle; the red triangles on green lines represent cycle slips of GPS PRN 2, 12, and 18 satellites. The thick straight line with colors represents reference satellites; the red triangles on the thick straight lines represent cycle slips of the reference satellites
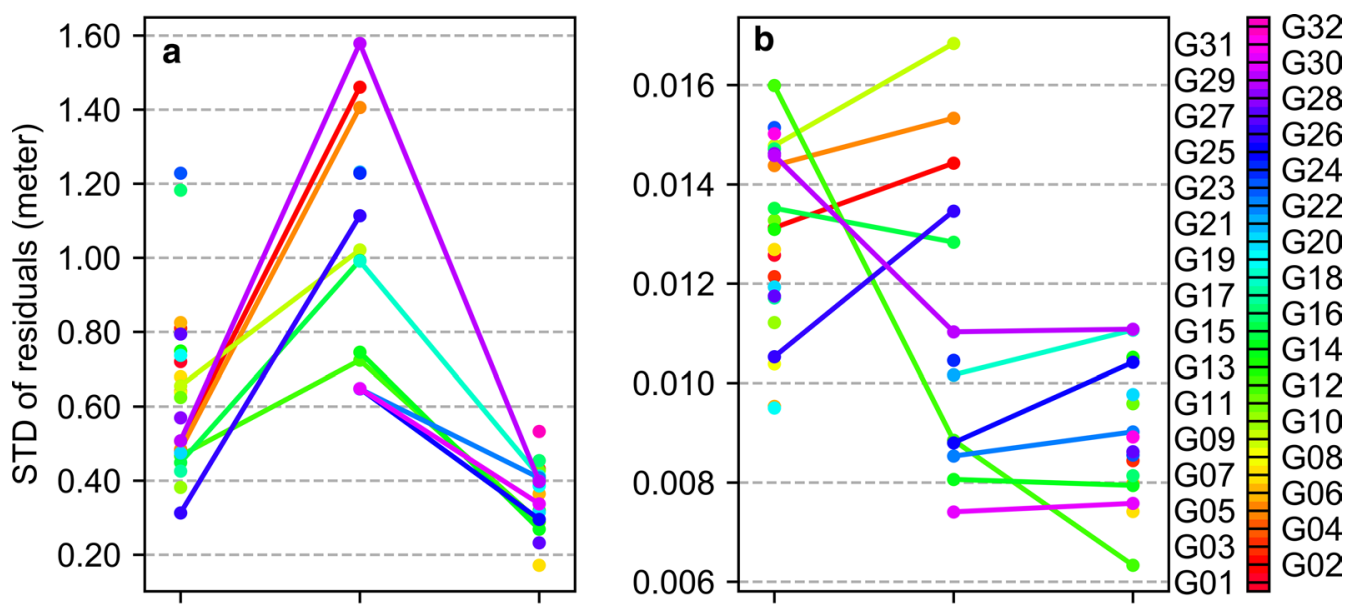

UT 00:00-12:0012:00-18:0018:00-24:00 UT 00:00-12:0012:00-18:0018:00-24:00

LT 08:00-20:0020:00-02:0002:00-08:00 LT 08:00-20:00 20:00-02:0002:00-08:00

$$
24 \text { September } 2013
$$

Fig. 17 STD of residuals on ionosphere-free pseudorange (a) and carrier phase (b) measurements from three periods (1) 00:00-12:00 UT; (2) 12:00-18:00 UT; (3) 18:00-24:00 UT for the baseline HKPC-HKOH on 24 September 2013. The isolated points without linkage with other points mean that the satellites are just visible in one of the three periods 
of the RMS of $0.042 \mathrm{~m}$ on the ionosphere quiet day. The degraded positioning performance was attributed to the poor GPS measurement, which was caused by the unstable ionospheric environment. Furthermore, the ionospheric disturbances were most probably triggered by the TC Usagi making landfall.

\begin{abstract}
Abbreviations
GPS: Global Positioning System; TC: Tropical cyclone; TEC: Total electron content; TECR: TEC rate; PPP: Precise point positioning; RMS: Root mean square; TECU: TEC unit; AGW: Acoustic gravity wave; HKO: Hong Kong Observatory; SatRef: Satellite Positioning Reference Station Network; WGS: World Geodetic System; ISMR: Ionospheric scintillation monitoring receiver; DEM: Digital elevation model; SI: Signal intensity; SNR: Signal-noise ratio; MWWL: Melbourne-Wübbena wide lane; LOS: Line of sight; STD: Standard deviation; PRN: Pseudorandom noise; NOAA: National Oceanic and Atmospheric Administration; NASA: National Aeronautics and Space Administration; GOES: Geostationary Operational Environmental Satellite; SEP: Solar energetic particle; IGS: International Global Navigation Satellite System Service.
\end{abstract}

\section{Acknowledgements}

The grant support from the Key Program of the National Natural Science Foundation of China (project No.: 41730109) is acknowledged. The grant supports from the Hong Kong Research Grants Council (RGC) projects (B-Q61L RGC/Gov No. PolyU 152222/17E) are highly appreciated. The Emerging Frontier Area (EFA) Scheme of Research Institute for Sustainable Urban Development (RISUD) of the Hong Kong Polytechnic University under Grant 1-BBWJ is acknowledged.

\section{Authors' contributions}

All authors contributed to the study conception and design. Material preparation, data collection and analysis were performed by SY. The first draft of the manuscript was written by SY. The critical review and revision were completed by ZL. ZL incubated the idea of this work and provided project funding support to this work. All authors commented on previous versions of the manuscript. All authors read and approved the final manuscript.

\section{Funding}

This work was supported by the Key Program of the National Natural Science Foundation of China (project No:: 41730109), the Hong Kong Research Grants Council (RGC) projects (B-Q61L RGC/Gov No. PolyU 1522222/17E). This work was also supported by the Emerging Frontier Area (EFA) Scheme of Research Institute for Sustainable Urban Development (RISUD) of the Hong Kong Polytechnic University under Grant 1-BBWJ.

\section{Availability of data and materials}

All data in this study are publicly available and free of charge. The Lands Department of the Government of Hong Kong Special Administrative Region (HKSAR) is acknowledged for providing the GPS data from the Hong Kong Satellite Positioning Reference Station Network (SatRef) (https://www.geode tic.gov.hk/en/rinex/downv.aspx). The International GNSS Service (IGS) is acknowledged for providing the GPS satellites' daily precise orbit and clock products from the $\mathrm{ftp}$ address $\mathrm{ftp}: / /$ /cddis.gsfc.nasa.gov/gps/products/ during the period of 14 September to 2 October 2013. The National Oceanic and Atmospheric Administration (NOAA) is also acknowledged for providing the International Best Track Archive for climate Stewardship (IBTrACS) data on the tropical cyclones (https://www.ncei.noaa.gov/data/international-best-track -archive-for-climate-stewardship-ibtracs/v04r00/access/csv/). In addition, we also would like to thank the Japan Aerospace Exploration Agency (JAXA) (https://www.eorc.jaxa.jp/ptree/userguide.html) for providing Himawari data. We also acknowledge use of NASA/GSFC's Space Physics Data Facility's OMNIWeb service (https://omniweb.gsfc.nasa.gov/form/dx1.html). The National Oceanic and Atmospheric Administration (NOAA)/National Aeronautics and Space Administration (NASA) is also acknowledged for providing the Solar-related data of Geostationary Operational Environmental Satellite (GOES) 15 satellite, which are available at the website (http://www.ngdc.noaa.gov/ $\mathrm{stp} /$ satellite/goes/dataaccess.html). For feasibility, the data used in this study have been uploaded to the public domain repository, i.e., Figshare, which is a free data repository open to the public. The daily GPS data in the format of Receiver Independent Exchange Format (RINEX) 2.11 during the period from 14 September to 2 October 2013 can be downloaded from https:// doi.org/10.6084/m9.figshare.12860837.v1. The corresponding GPS satellites' daily precise orbit (.sp3) and clock (.clk_30s) products can be downloaded from https://doi.org/10.6084/m9.figshare.12860903.v1. The records of the tropical cyclone Usagi 2013 can be downloaded from https://doi.org/10.6084/ m9.figshare.12860906.v1. The Himawari 7 image at 12:00 UT on September 22, 2013 can be downloaded from https://doi.org/10.6084/m9.figshare.12860 897.v1. The indices of Kp, Dst, and F10.7 during the period from 13 September to 2 October 2013 can be downloaded from https://doi.org/10.6084/m9.figsh are.12860912.v1. The scintillation data of the lonospheric Scintillation Monitoring Receiver (ISMR) in Hong Kong can be downloaded from https://doi. org/10.6084/m9.figshare.12860921.v1. The Solar-related parameters including X-ray flux, solar X-ray flare counts, and electron flux from 13 September to 12 October 2013 can be downloaded from https://doi.org/10.6084/m9.figsh are.13204886.v1

\section{Declarations}

Ethics approval and consent to participate

Not applicable.

\section{Consent for publication}

Not applicable.

\section{Competing interests}

The authors declare that they have no competing interests.

\section{Author details}

${ }^{1}$ Department of Land Surveying and Geo-Informatics, The Hong Kong Polytechnic University, Hong Kong, China. ${ }^{2}$ Research Institute for Sustainable Urban Development, The Hong Kong Polytechnic University, Hong Kong, China.

Received: 7 September 2020 Accepted: 25 February 2021

Published online: 09 March 2021

\section{References}

Brunini C, Azpilicueta F (2010) GPS slant total electron content accuracy using the single layer model under different geomagnetic regions and ionospheric conditions. J Geod 84(5):293-304. https://doi.org/10.1007/ s00190-010-0367-5

Cai C, Liu Z, Xia P, Dai W (2013) Cycle slip detection and repair for undifferenced GPS observations under high ionospheric activity. GPS Solut 17(2):247-260. https://doi.org/10.1007/s10291-012-0275-7

Chan K, Li C (2007) The Hong Kong Satellite Positioning Reference Station Network (SatRef) - System Configurations, Applications and Services

Chen W, Gao S, Hu C, Chen Y, Ding X (2008) Effects of ionospheric disturbances on GPS observation in low latitude area. GPS Solut 12(1):33-41. https://doi. org/10.1007/s10291-007-0062-z

Chen CH, Saito A, Lin CH, Yamamoto M, Suzuki S, Seemala GK (2016) Mediumscale traveling ionospheric disturbances by three-dimensional ionospheric GPS tomography 3 Space science. Earth Planets Space. https://doi. org/10.1186/s40623-016-0412-6

Chou MY, Lin CCH, Yue J, Tsai HF, Sun YY, Liu JY, Chen CH (2017) Concentric traveling ionosphere disturbances triggered by Super Typhoon Meranti (2016). Geophys Res Lett 44(3):1219-1226. https://doi.org/10.1002/2016GL072205

Čokrlić M, Galas R (2013) TUB software tools for monitoring ionospheric irregularities in a single station mode and first results. In: Proceedings of 7th European Conference on Antennas and Propagation (EUCAP). IEEE, Gothenburg, Sweden, pp 3673-3676

Forsyth C, Watt CEJ, Mooney MK, Rae IJ, Walton SD, Horne RB (2020) Forecasting GOES $15>2$ MeV electron fluxes from solar wind data and geomagnetic indices. Space Weather 18(8):e2019SW002416. https://doi. org/10.1029/2019SW002416

Gordon WE (1987) The propagation of radio waves: the theory of radio waves of low power in the ionosphere and magnetosphere. Eos Trans Am Geophys Union 68(12):164-165. https://doi.org/10.1029/EO068i012p00164-03 
Guha A, Paul B, Chakraborty M, De BK (2016) Tropical cyclone effects on the equatorial ionosphere: First result from the Indian sector. J Geophys Res Space Phys 121(6):5764-5777. https://doi.org/10.1002/2016JA022363

Gulyaeva T, Arikan F (2017) Statistical discrimination of global post-seismic ionosphere effects under geomagnetic quiet and storm conditions. Geomat Nat Hazards Risk 8(2):509-524. https://doi.org/10.1080/19475705.2016.1246483

Guo K, Liu Y, Zhao Y, Wang J (2017) Analysis of ionospheric scintillation characteristics in sub-Antarctica region with GNSS data at Macquarie Island. Sensors. https://doi.org/10.3390/s17010137

Hong Kong Observatory (2015) Tropical Cyclones in 2013. Hong Kong Observatory, Hong Kong. https://www.hko.gov.hk/en/publica/tc/files/TC2013.pdf. Accessed Feb 2015

Ke F, Wang J, Tu M, Wang X, Wang X, Zhao X, Deng J (2019) Characteristics and coupling mechanism of GPS ionospheric scintillation responses to the tropical cyclones in Australia. GPS Solut 23(2):34. https://doi.org/10.1007/ s10291-019-0826-2

Kong J, Yao Y, Xu Y, Kuo C, Zhang L, Liu L, Zhai C (2017) A clear link connecting the troposphere and ionosphere: ionospheric responses to the 2015 Typhoon Dujuan. J Geod 91(9):1087-1097. https://doi.org/10.1007/s0019 0-017-1011-4

Lastovicka J (2009) Lower ionosphere response to external forcing: a brief review. Adv Space Res 43(1):1-14. https://doi.org/10.1016/j.asr.2008.10.001

Leick A, Rapoport L, Tatarnikov D (2015) GPS satellite surveying, 3rd edn. Wiley, New York

Li W, Yue J, Yang Y, Li Z, Guo J, Pan Y, Zhang K (2017) Analysis of ionospheric disturbances associated with powerful cyclones in East Asia and North America. J Atmospheric Sol-Terr Phys 161:43-54. https://doi.org/10.1016/j. jastp.2017.06.012

Li W, Yue J, Wu S, Yang Y, Li Z, Bi J, Zhang K (2018) lonospheric responses to typhoons in Australia during 2005-2014 using GNSS and FORMOSAT-3/ COSMIC measurements. GPS Solut 22(3):61. https://doi.org/10.1007/s1029 $1-018-0722-1$

Liu Z (2011) A new automated cycle slip detection and repair method for a single dual-frequency GPS receiver. J Geod 85(3):171-183. https://doi.org/10.1007/ s00190-010-0426-y

Liu Z, Xu R, Morton Y, Xu J, Pelgrum W, Taylor S, Chen W, Ding X (2013) A Comparison of GNSS-based lonospheric Scintillation Observations in North and South Hong Kong. In: Proceedings of the ION 2013 Pacific PNT Meeting. Honolulu, Hawaii, USA, pp 694-705

Lou Y, Luo X, Gu S, Xiong C, Song Q, Chen B, Xiao Q, Chen D, Zhang Z, Zheng G (2019) Two typical ionospheric irregularities associated with the tropical cyclones Tembin (2012) and Hagibis (2014). J Geophys Res Space Phys 124(7):6237-6252. https://doi.org/10.1029/2019JA026861

Luo X, Lou Y, Xiao Q, Gu S, Chen B, Liu Z (2018) Investigation of ionospheric scintillation effects on BDS precise point positioning at low-latitude regions. GPS Solut 22(3):63. https://doi.org/10.1007/s10291-018-0728-8

Moeketsi DM, Combrinck WL, McKinnell LA, Fedrizzi M (2007) Mapping GPSderived ionospheric total electron content over Southern Africa during different epochs of solar cycle 23. Adv Space Res 39(5):821-829. https://doi. org/10.1016/j.asr.2007.01.065

Muella MTAH, de Paula ER, Kantor IJ, Batista IS, Sobral JHA, Abdu MA, Kintner PM, Groves KM, Smorigo PF (2008) GPS L-band scintillations and ionospheric irregularity zonal drifts inferred at equatorial and low-latitude regions. J Atmospheric Sol-Terr Phys 70(10):1261-1272. https://doi.org/10.1016/j.jastp 2008.03 .013

Mukhtarov PI, Andonov B, Borries C, Pancheva D, Jakowski N (2010) Forcing of the ionosphere from above and below during the Arctic winter of 2005/2006. J Atmospheric Sol-Terr Phys 72(2-3):193-205. https://doi.org/10.1016/j.jastp .2009.11.008
Mungufeni P, Habarulema JB, Jurua E (2016) Trends of ionospheric irregularities over African low latitude region during quiet geomagnetic conditions. J Atmospheric Sol-Terr Phys 138-139:261-267. https://doi.org/10.1016/j. jastp.2016.01.015

Mushini SC, Jayachandran PT, Langley RB, MacDougall JW, Pokhotelov D (2012) Improved amplitude- and phase-scintillation indices derived from wavelet detrended high-latitude GPS data. GPS Solut 16(3):363-373. https://doi. org/10.1007/s10291-011-0238-4

Nina A, Radovanovic M, Milovanovic B, Kovacevic A, Bajcetic J, Popovic LC (2017) Low ionospheric reactions on tropical depressions prior hurricanes. Adv Space Res 60(8):1866-1877. https://doi.org/10.1016/j.asr.2017.05.024

Perevalova NP, Ishin AB (2011) Effects of tropical cyclones in the ionosphere from data of sounding by GPS signals. Izv Atmospheric Ocean Phys 47(9):10721083. https://doi.org/10.1134/S000143381109012X

Polyakova AS, Perevalova NP (2011) Investigation into impact of tropical cyclones on the ionosphere using GPS sounding and NCEP/NCAR Reanalysis data. Adv Space Res 48(7):1196-1210. https://doi.org/10.1016/j.asr.2011.06.014

Rostoker G (1972) Geomagnetic indices. Rev Geophys 10(4):935-950. https://doi. org/10.1029/RG010i004p00935

Song Q, Ding F, Zhang X, Mao T (2017) GPS detection of the ionospheric disturbances over China due to impacts of Typhoons Rammasum and Matmo. J Geophys Res Space Phys 122(1):1055-1063. https://doi. org/10.1002/2016JA023449

Tapping KF (2013) The 10.7 cm solar radio flux (F10. 7). Space Weather 11(7):394406. https://doi.org/https://doi.org/10.1002/swe.20064

Van Dierendonck A, Klobuchar J, Hua Q (1993) lonospheric scintillation monitoring using commercial single frequency C/A code receivers. In: Proceedings of Institute of Navigation Global Positioning System (ION GPS). Salt Lake City, Utah, USA, pp 1333-1342

Vanina-Dart LB, Sharkov EA (2016) Main results of recent investigations into the physical mechanisms of the interaction of tropical cyclones and the ionosphere. Izv Atmospheric Ocean Phys 52(9):1120-1127. https://doi. org/10.1134/S0001433816090279

Wang Z, Wang X, Ji S, Chen W (2016) Optimal cycle slip detection and correction with reliability. Surv Rev 48(349):233-239. https://doi.org/10.1179/17522 $70615 y .0000000024$

Xiao Z, Xiao S, Hao Y, Zhang D (2007) Morphological features of ionospheric response to typhoon. J Geophys Res-Space Phys 112(A4). https://doi. org/https://doi.org/10.1029/2006JA011671

Xu R, Liu Z, Li M, Yu M, Chen W (2012) An analysis of low-latitude ionospheric scintillation and its effects on precise point positioning. J Glob Position Syst 11(1):22-32

Yang Z, Liu Z (2016a) Observational study of ionospheric irregularities and GPS scintillations associated with the 2012 tropical cyclone Tembin passing Hong Kong. J Geophys Res Space Phys 121(5):4705-4717. https://doi. org/10.1002/2016JA022398

Yang Z, Liu Z (2016b) Correlation between ROTI and Ionospheric Scintillation Indices using Hong Kong low-latitude GPS data. GPS Solut 20(4):815-824. https://doi.org/10.1007/s10291-015-0492-y

Zhang X, Guo F, Zhou P (2014) Improved precise point positioning in the presence of ionospheric scintillation. GPS Solut 18(1):51-60. https://doi. org/10.1007/s10291-012-0309-1

\section{Publisher's Note}

Springer Nature remains neutral with regard to jurisdictional claims in published maps and institutional affiliations. 